\title{
Incidence of Benign Lesions According to Tumor Size in Solid Renal Masses
}

\author{
Victor Srougi, Raphael B. Kato, Fernanda A. Salvatore, Pedro P.M. Ayres, Marcos F. Dall'Oglio, \\ Miguel Srougi
}

Division of Urology, University of Sao Paulo Medical School, Sao Paulo, SP, Brazil

\begin{abstract}
Objective: The incidence of solid renal masses has increased sharply in recent years due to widespread use of abdominal imaging studies. The aim of the present study was to evaluate the incidence of benign lesions in solid renal masses according to tumor size.

Materials and Methods: The authors retrospectively reviewed the records of 305 patients with 328 renal solid masses treated by surgery. Based on a report by one pathologist, the specimen tumor size and the histology of each lesion were tabulated. The frequency of renal cell carcinoma and benign renal lesions was evaluated and a correlation between tumor size and pathological features of the masses was observed.

Results: The frequency of malignant lesions in the 328 renal masses was $83.2 \%$. When lesions were stratified into groups with diameters $\leq 3 \mathrm{~cm}$ or $>3 \mathrm{~cm}$, the incidence of benign histology was $22.9 \%$ and $13.3 \%$, respectively $(\mathrm{p}=0.026)$. The odds ratios for finding a benign lesion in masses $\leq 3 \mathrm{~cm}$ was 1.93 (IC 95\%, $1.07-3.46$ ) compared to masses $>3 \mathrm{~cm}$. Conclusion: The incidence of benign lesions is significantly higher in renal masses smaller than $3 \mathrm{~cm}$ in diameter, which should be taken in account when the treatment of renal solid masses is planned.
\end{abstract}

Key words: renal cell, carcinoma; staging; mass; benign; imaging

Int Braz J Urol. 2009; 35: 427-31

\section{INTRODUCTION}

Renal cell carcinomas (RCCs) represent between $3 \%$ and $4 \%$ of neoplasms found in clinics (1) and their incidence has been rising about 3\% per year since 1975 (2). In the past, $85 \%$ of the expansive lesions found in kidneys were related to RCC, while the remaining lesions were benign local disorders (3). In recent years, with the introduction of new imaging methods like ultrasound, CAT scan, and magnetic resonance, there has been a significant increase in the detection of asymptomatic and incidental renal tumors, cases that now outnumber tumors identified after the onset of symptoms. Currently, up to $71 \%$ of the solid renal masses are found incidentally during abdominal imaging studies $(2,3)$. In these cases, the lesions are usually smaller and are frequently benign (4-7).

The finding of benign disorders in a significant number of patients with solid renal masses has practical implications that cannot be ignored. The adoption of indiscriminate surgical treatment in all cases of renal masses will result in unnecessary interventions and even the undue loss of kidneys in patients without malignant disease. To avoid this dilemma, many authors advise a pre-op percutaneous biopsy in cases of solid renal masses $(8,9)$. Although these tests are highly accurate, biopsy is not sufficiently 


\section{Benign Lesions in Renal Solid Masses}

accurate in all cases and can fail in characterizing the histology of renal masses (10).

We have conducted this study in order to guide medical judgment and to more efficiently handle solid renal masses by attempting to determine if certain mass tumors can be treated non-surgically. This would provide for the development of a criterion other than the biopsy to help the therapeutic decision process for patients with renal masses.

\section{MATERIALS AND METHODS}

The present study is a retrospective analysis of 305 consecutive patients seen at our Institution from 1977 to 2006, bearing incidentally or symptomatic solid renal masses.

A total of 305 patients were evaluated, including 231 males and 74 females ranging in age from 9 to 90 years (median of 60 years). All of the patients had expansive kidney lesions depicted by computerized axial tomography or magnetic resonance imaging; some were solid and others had intermingled large solid and small cystic areas. In the patients with multiple lesions, each one was studied individually and a total of 328 lesions were analyzed. Taking in account the clinical presentation, the routine blood and urinary tests and the imaging studies, all lesions classified as inflammatory or infectious were excluded from the study.

All patients were operated upon by the same surgeon (MS) and included radical nephrectomy (213 pts), partial nephrectomy (24 pts), or mass enucleation (68 pts). The surgical specimens were analyzed by the same pathologist, using the UICC histopathology classification for RCC, including clear cell, chromophobe, papillary, Bellini duct, and sarcomatoid subtypes (11).

Using the primary clinical outcome, an attempt has been made to define the total incidence of benign lesions and correlate the tumor diameter with final histology of the lesion. The diameter was measured in the surgical specimen, taking into account the greatest diameter found. The histopathology findings were divided into benign and malignant categories, and the frequency of these two types was compared to original nodes of greater or less than $3 \mathrm{~cm}$ in diameter.
The differences in proportion of benign and malignant lesions in the groups with diameters of more or less than $3 \mathrm{~cm}$ were evaluated by statistical analysis with the chi-square test, adopting a significance level of $5 \%(\mathrm{p}<0.05)$ for rejecting the null hypothesis. The strength of association between the two variables was analyzed by an odds ratio calculation with a confidence interval of $95 \%$ (IC at 95).

\section{RESULTS}

In this study, the diameter of the evaluated lesions ranged from $0.2 \mathrm{~cm}$ to $24.0 \mathrm{~cm}$, with a median of $4.0 \mathrm{~cm}$. According to Table-1, among the 328 renal lesions found in 305 patients, 273 (83.2\%) were renal cell carcinomas. In the other cases, $43(13.2 \%)$ were benign lesions and $12(3.6 \%)$ were non-neoplasic lesions.

When the incidence of benign lesions was evaluated as a function of the renal mass diameter, a frequency of $13.3 \%$ and $22.9 \%$ was observed, respectively, in the masses with diameters equal or greater and smaller than $3 \mathrm{~cm}$ (Tables 2 and 3 ) with a statistically significant difference between the frequency of benign pathologies and the lesion size ( $p$ $=0.026$ ). These same numbers show that the chance of finding a malignant lesion in nodes greater than $3 \mathrm{~cm}$ in diameter is 1.93 times greater (IC at 95\%, 1.07-3.46) than in nodes with diameters of $3 \mathrm{~cm}$.

Table 1 - Pathological findings in 328 renal masses.

\begin{tabular}{lrc}
\hline Diagnosis & $\mathbf{N}$ & $\mathbf{\%}$ \\
\hline Renal cell carcinoma & 273 & 83.2 \\
Oncocytoma & 23 & 71 \\
Angiomyolipoma & 14 & 4.3 \\
Multilocular cyst & 8 & 2.4 \\
Cystic nephroma & 3 & 0.9 \\
Hematoma & 2 & 0.6 \\
Renal infarct & 2 & 0.6 \\
Hemangioma & 1 & 0.3 \\
Metanephric adenoma & 1 & 0.3 \\
Leiomyoma & 1 & 0.3 \\
Total & 328 & 100.00 \\
\hline
\end{tabular}


Table 2 - Surgical specimen lesion size and pathological findings.

\begin{tabular}{lcrc}
\hline Lesion Size $(\mathrm{cm})$ & Total Number & N Malignant & Pathology \\
& & $91(77.1 \%)$ & N Benign \\
\hline$\leq 3.0$ & 118 & $182(86.7 \%)$ & $27(22.9 \%)$ \\
$>3.0$ & 210 & $273(83.2 \%)$ & $55(13.3 \%)$ \\
Total & 328 & & $55.8 \%)$ \\
\hline
\end{tabular}

\section{COMMENTS}

This study shows that there is a true correlation between the diameter or solid renal nodes and the incidence of benign lesions. To perform our analysis we compared lesion smaller or larger than 3 $\mathrm{cm}$ and we choose this cut-off value because it has been demonstrated that it correlates well with the risks of metastatic disease in renal cell carcinoma. Metastatic disease is usually found in tumors larger than $3 \mathrm{~cm}$ (12) which makes this threshold a valuable clinical parameter for handling patients with solid renal lesions. Benign lesions were seen in $13.3 \%$ of 210 (two hundred and ten) masses less than $3 \mathrm{~cm}$ in diameter and in $22.9 \%$ of 118 nodes greater than $3 \mathrm{~cm}$ in diameter. We believe these results are significant, as the present study included a large number of patients, the surgical specimens were all analyzed by a single pathologist, and the largest tumor diameter was measured in the surgical specimen. Some previous studies published regarding the same subject evaluated a smaller number of cases $(13,14)$ and the measurement

Table 3 - Frequency of benign disease for every cm increase in tumor diameter.

\begin{tabular}{lcc}
\hline $\begin{array}{l}\text { Lesion Size } \\
(\mathrm{cm})\end{array}$ & $\begin{array}{c}\text { Total } \\
\text { Number }\end{array}$ & $\begin{array}{c}\text { Pathology } \\
\text { N Benign (\%) }\end{array}$ \\
\hline$\leq 2.0$ & 47 & $16(34.0 \%)$ \\
$2.1-4.0$ & 122 & $16(13.1 \%)$ \\
$4.1-6.0$ & 70 & $12(17.1 \%)$ \\
$6.1-8.0$ & 36 & $4(11.1 \%)$ \\
$8.1-10.0$ & 25 & $4(16.0 \%)$ \\
$\geq 10.0$ & 28 & $3(10.7 \%)$ \\
\hline
\end{tabular}

of the tumor size was made by imaging studies that show a certain variability due to heterogeneous cuts and random radiologist readings $(3,15,16)$.

The greatest frequency of benign lesions in renal masses smaller than $3 \mathrm{~cm}$ found in our study agrees with other studies previously published $(4,6,7,15)$. According to those studies, between $12.5 \%$ and $46.3 \%$ of solid renal nodes less than $3 \mathrm{~cm}$ in diameter are benign, and this frequency decreases, from $0 \%$ to $19.9 \%$, when the solid mass is more than $3 \mathrm{~cm}$ in diameter $(7,15)$. A single study, published by Snyder et al., has shown the absence of correlation between the size of renal nodes and the incidence of benign lesions. However, this study excluded greater diameter masses, a fact that probably reduced the number of malignant lesions in this sub-group when the patients were treated surgically (16).

One of the main limitations of the present study is that only tumor size was taken in account to predict the pathological outcome of the solid renal masses. It has been already shown that other relevant variables such as other radiological features, clinical presentation, age, gender or tumor growth velocity can help in the differential diagnosis of renal tumors $(17,18)$. On the other hand, renal tumor size correlates with the risks of metastasis and with patient survival. Furthermore measuring tumor diameter is a simple way that helps physician to plan patient care when a more detailed analysis of imaging studies are not available or are incomplete.

Fifty-five of the 328 lesions (16.8\%) evaluated in our study represented benign disorders, with a prevalence of oncocytomas (7.1\%) and angiomyolipomas $(4.3 \%)$. This distribution is similar to that seen in other studies $(15,16)$, showing that although there is an absence of aggressiveness, most of the benign renal lesions found in practice are neoplasic in nature, with 
a possibility of generating difficulties in interpretation when percutaneous biopsies are diagnosed in patients with solid renal lesions. In fact, in one of the contemporary series of percutaneous biopsies to study renal masses, $21 \%$ of the cases did not have the etiology defined on the first attempt, generating problems in terms of an effective therapeutic intervention (8).

According to the data of the present study, it is important for specialists to consider the possibility of benign lesions when identifying solid or mixed renal nodes. The incidence of benign lesions is significantly greater in solid renal masses with diameters of less than $3 \mathrm{~cm}$ and this must be taken into account when advising patients about the relevance of the disease and about treatment options. In lesions with diameters less than $3 \mathrm{~cm}$, the frequency of benign masses is almost twice as common as that found in greater masses. This finding can be relevant when we are treating patients with multiple bilateral small solid nodules or patients unsuited for surgery. In these settings, the use of percutaneous lesion biopsies has a great chance to show a benign lesion and this finding will obviate the need for an unnecessary surgical intervention (9). Furthermore, the adoption of surveillance in a patient with a solid renal mass can be done with less concern if the lesion has less than $3 \mathrm{~cm}$ in diameter. Considering that such tumors have no or negligible growth when followed for years (19), based on tumor size and tumor growth physicians can safely monitor their patients treated with active surveillance.

\section{ACKNOWLEDGEMENT}

Adriana Sañudo performed the statistical analyses.

\section{CONFLICT OF INTEREST}

None declared.

\section{REFERENCES}

1. Jemal A, Siegel R, Ward E, Hao Y, Xu J, Murray T, et al.: Cancer statistics, 2008. CA Cancer J Clin. 2008; 58: 71-96.
2. Chow WH, Devesa SS, Warren JL, Fraumeni JF Jr: Rising incidence of renal cell cancer in the United States. JAMA. 1999; 281: 1628-31.

3. Pahernik S, Ziegler S, Roos F, Melchior SW, Thüroff JW: Small renal tumors: correlation of clinical and pathological features with tumor size. J Urol. 2007; 178: 414-7; discussion 416-7.

4. Glassman D, Chawla SN, Waldman I, Johannes J, Byrne DS, Trabulsi EJ, et al.: Correlation of pathology with tumor size of renal masses. Can J Urol. 2007; 14: 3616-20.

5. Dall'Oglio M, Srougi M, Ortiz V, Nesrallah L, Gonçalves PD, Leite KM, et al.: Incidental and symptomatic kidney cancer: pathological features and survival. Rev Assoc Med Bras. 2004; 50: 27-31.

6. Schachter LR, Cookson MS, Chang SS, Smith JA Jr, Dietrich MS, Jayaram G, et al.: Second prize: frequency of benign renal cortical tumors and histologic subtypes based on size in a contemporary series: what to tell our patients. J Endourol. 2007; 21: 819-23.

7. Frank I, Blute ML, Cheville JC, Lohse CM, Weaver $\mathrm{AL}$, Zincke H: Solid renal tumors: an analysis of pathological features related to tumor size. J Urol. 2003; 170: 2217-20.

8. Lebret T, Poulain JE, Molinie V, Herve JM, Denoux Y, Guth A, et al.: Percutaneous core biopsy for renal masses: indications, accuracy and results. J Urol. 2007; 178: 1184-8; discussion 1188.

9. Volpe A, Kachura JR, Geddie WR, Evans AJ, Gharajeh A, Saravanan A, et al.: Techniques, safety and accuracy of sampling of renal tumors by fine needle aspiration and core biopsy. J Urol. 2007; 178: 379-86.

10. Dechet CB, Zincke H, Sebo TJ, King BF, LeRoy AJ, Farrow GM, et al.: Prospective analysis of computerized tomography and needle biopsy with permanent sectioning to determine the nature of solid renal masses in adults. J Urol. 2003; 169: 71-4.

11. Störkel S, Eble JN, Adlakha K, Amin M, Blute ML, Bostwick DG, et al.: Classification of renal cell carcinoma: Workgroup No. 1. Union Internationale Contre le Cancer (UICC) and the American Joint Committee on Cancer (AJCC). Cancer. 1997; 80: 987-9.

12. Kunkle DA, Crispen PL, Li T, Uzzo RG: Tumor size predicts synchronous metastatic renal cell carcinoma: implications for surveillance of small renal masses. J Urol. 2007; 177: 1692-6; discussion 1697.

13. Kutikov A, Fossett LK, Ramchandani P, Tomaszewski JE, Siegelman ES, Banner MP, et al.: Incidence of benign pathologic findings at partial nephrectomy for solitary renal mass presumed to be renal cell car- 


\section{Benign Lesions in Renal Solid Masses}

cinoma on preoperative imaging. Urology. 2006; 68: $737-40$

14. Harada K, Sakai I, Ishimura T, Inoue TA, Hara I, Miyake H: Clinical symptoms in localized renal cell carcinoma reflect its invasive potential: comparative study between incidentally detected and symptomatic diseases. Urol Oncol. 2006; 24: 201-6.

15. Schlomer B, Figenshau RS, Yan Y, Venkatesh R, Bhayani SB: Pathological features of renal neoplasms classified by size and symptomatology. J Urol. 2006; 176: 1317-20; discussion 1320 .

16. Snyder ME, Bach A, Kattan MW, Raj GV, Reuter VE, Russo P: Incidence of benign lesions for clinically localized renal masses smaller than $7 \mathrm{~cm}$ in radiological diameter: influence of sex. J Urol. 2006; 176: 2391-5; discussion 2395-6.

17. Lane BR, Kattan MW: Prognostic models and algorithms in renal cell carcinoma. Urol Clin North Am. 2008; 35: 613-25.

18. Volpe A: The role of surveillance in the management of small renal masses. ScientificWorldJournal. 2007; 7: 860-8.

19. Volpe A, Panzarella T, Rendon RA, Haider MA, Kondylis FI, Jewett MA.: The natural history of incidentally detected small renal masses. Cancer. 2004; 100: 738-45.

\section{Correspondence address:}

Dr. Miguel Srougi

Rua Barata Ribeiro, 414, $7^{\circ}$ andar

São Paulo, SP, 01308-000, Brazil

E-mail: srougi@uol.com.br 